\title{
Induction of Estrogen Receptor $\beta$-mediated Autophagy Sensitizes Breast Cancer Cells to TAD1822-7, a Novel Biphenyl Urea Taspine Derivative
}

\section{Qi Su}

School of Pharmacy

Qing Wu

School of Pharmacy

Kun Chen

School of Pharmacy

Jingjing Wang

School of Pharmacy

Ammar Sarwar

School of Pharmacy

Yanmin Zhang ( $\nabla$ zhang2008@mail.xjtu.edu.cn )

Xi'an Jiaotong University https://orcid.org/0000-0001-7307-9408

\section{Research Article}

Keywords: Estrogen receptor $\beta$, Autophagy , Cell death , Breast cancer , TAD1822-7, Hypoxia

Posted Date: August 27th, 2021

DOl: https://doi.org/10.21203/rs.3.rs-701049/v1

License: (c) (1) This work is licensed under a Creative Commons Attribution 4.0 International License.

Read Full License

Version of Record: A version of this preprint was published at Molecular Biology Reports on November 18th, 2021. See the published version at https://doi.org/10.1007/s11033-021-06950-5. 


\section{Abstract}

Female breast cancer has become the most commonly diagnosed cancer worldwide. As a tumor suppressor, estrogen receptor $\beta$ (ER $\beta)$ is a potential target for breast cancer therapy. TAD1822-7 was evaluated for ERß-mediated autophagy and cell death using cell proliferation assay, Annexin V/PI staining, immunofluorescence, western blotting and hypoxia cell models. TAD1822-7 upregulated ER $\beta$ causing cell death and induced mitochondrial dysfunction and autophagy companied with mitochondrial located ERß. Enhanced levels of LC3-II and p62 indicated that TAD1822-7 blocked the late-stage autolysosome formation, leading to cell death. Mechanistically, TAD1822-7-induced cell death was mediated by PI3K/AKT signaling pathways. Moreover, TAD1822-7 modulated HIF functions and autophagy via the inhibition of HIF-1 $\beta$ in the context of hypoxia-induced autophagy. TAD1822-7 inhibited hypoxia-inducted autophagy and PI3K/AKT pathway. These findings provide new insight into the mechanism underlying the inhibitory effects of TAD1822-7 via ERß-mediated pathways in breast cancer cells.

\section{Introduction}

Female breast cancer, a malignancy originating from mammary epithelial tissue, has surpassed lung cancer as the most commonly diagnosed cancer in 2020 [1]. The discovery and characterizing of estrogen receptors (ER), especially ERa, allow widely use in determining medication and imaging strategies [2]. On the contrary to the tumor-promoting ERa, ERß has been shown to act as a tumor suppressor and proposed as a potential target for breast cancer therapy, since the widespread expression of ER $\beta$ is detected not only in luminal breast cancers but also in triple-negative breast cancers [3, 4]. However, the exact role of ER $\beta$ in breast cancer carcinogenesis and progression still needs to be further elucidated.

Autophagy plays a key role in the maintenance of cellular homeostasis and dysregulation of autophagy has been implicated in cancers [5]. Emerging studies have suggested that ER $\beta$ activation could trigger autophagy monitored by the conversion of LC3-I to LC3-II, which contributes to the inhibition of breast cancer cell proliferation, migration and invasion [6, 7]. p62/SQSTM1 (p62) acts as an autophagy adaptor that mediates the selective recognition and degradation of autophagy substrates by bridging the substrate with LC3 proteins. Following delivery to the lysosome, p62 is degraded with its substrates therefore used as a marker to study autophagy flow [8]. The role of ER $\beta$ in p62 regulation is yet to determine to clarify how ERß modulate autophagy in breast cancer cells. Hypoxia is one of the key features of tumor microenvironment and hypoxia-induced autophagy has been well documented $[9,10]$. Under hypoxia, HIF-1 $a$ and HIF-1 $\beta$ heterodimers translocate to the nucleus and activate downstream genes. In breast cancer cells, ER $\beta$ suppresses HIF-1 activation via the downregulation of HIF-1 [11], thus the regulation of ER $\beta$ may lead to the suppression of hypoxia-mediated autophagy and downstream pathways. 
Taspine was a natural alkaloid originally identified from the extracts of the root and rhizome of Caulophyllum robustum Maxim. (Hong Mao Qi in Chinese). It has many pharmacologic actions such as bacteriostasis, antibiosis, antivirus, anti-inflammatory and antiulcer. TAD1822-7 (N-(4'-acetyl-3',5,6trimethoxybiphenyl-3-yl)-N'-[4-(3-morpholin-4-ylpropoxy)phenyl]urea) (Fig. 1a) is a novel biphenyl taspine derivative designed and synthesized in our laboratory [12]. Previous studies have revealed the antitumor and antiangiogenesis effects in breast cancer cells. However, the regulatory properties of TAD1822-7 in the context of ERß-mediated pathways and autophagy have not been investigated. In this study, we found that TAD1822-7 could induce breast cancer cell death attributed to the upregulated ER $\beta$ expression and inhibition of PI3K/AKT pathways. Furthermore, TAD1822-7 triggered mitochondrial dysfunction and autophagy but blocked the late-stage autolysosome formation, thereby leading to cell death. In addition, TAD1822-7 inhibited hypoxia-inducted autophagy and PI3K/AKT pathway through the ERß-mediated downregulation of HIF-1 $\beta$.

\section{Materials And Methods}

\section{Chemicals and reagents}

TAD1822-7 was from the Research and Engineering Center for Natural Medicine, Xi'an Jiaotong University. RPMI, MTT, trypsin, DMSO were purchased from Sigma-Aldrich (St. Louis, MO, USA). Fetal bovine serum (FBS) was purchased from Excell Bio (Shanghai, China). Antibodies against ER $\beta$, p62, LC3, HIF-1 $\beta$ and $\beta$-actin were obtained from Proteintech Group, Inc (Wuhan, China), and antibodies against p110a, p110 $\beta$, p-p85, HIF-1a, p-AKT and AKT were purchased from Cell signaling (Boston, USA). All the antibodies were used in the dilution of 1:1000 for western blotting. RIPA Lysis Buffer was obtained from Applygen Technologies (Beijing, China). Protease and phosphatase inhibitor cocktail were purchased from Roche Technology (Basle, Switzerland). BCA protein assay reagent kit and enhanced chemiluminescent (ECL) plus reagent kit were obtained from Pierce Biotech (Rockford, Illinois, USA). Bafilomycin A1 (Baf), mdivi-1 (Mdv) and chloroquine diphosphate purchased from TargetMol (TargetMol Boston, USA). TMRE was obtained from Yeasen (Shanghai, China). Diarylpropionitrile (DPN) was obtained from Aladdin (Shanghai, China). Mitoorange was purchased from KeyGEN BioTECH (Jiangsu, China).

\section{Cell lines and cell culture}

Human breast cancer cell line T47D and MDA-MB-231 were obtained from Shanghai Institute of Cell Biology in the Chinese Academy of Sciences. T47D cells were cultured in RPMI-1640 medium with 10\% (v/v) FBS, supplemented with $100 \mathrm{unit} / \mathrm{ml}$ penicillin and $100 \mathrm{mg} / \mathrm{ml}$ streptomycin. Cells were maintained at $37{ }^{\circ} \mathrm{C}$ in a humidified incubator with $5 \% \mathrm{CO}_{2}$ in air. MDA-MB-231 cells were cultured in $\mathrm{L} 15$ medium with $10 \%(\mathrm{v} / \mathrm{v}) \mathrm{FBS}$, supplemented with $100 \mathrm{unit} / \mathrm{ml}$ penicillin and $100 \mathrm{mg} / \mathrm{ml}$ streptomycin. Cells were maintained at $37^{\circ} \mathrm{C}$ in a humidified incubator. For the hypoxic condition, cells were incubated at a $\mathrm{CO}_{2}$ level of $5 \%$ with $1 \% \mathrm{O}_{2}$ balanced with $\mathrm{N}_{2}$ using a hypoxic chamber.

\section{Western blotting}


Cells were lysed in RIPA buffer containing phosphatase/protease inhibitors. Protein concentrations were quantified with the BCA assay. The samples were subjected to SDS-PAGE and transferred to PVDF membranes (Millipore, Bedford, MA, USA), blocked with $5 \%$ non-fat milk and incubated with the indicated primary antibodies at $4^{\circ} \mathrm{C}$ overnight. Then the membrane was incubated with secondary antibodies and the expression was visualized using the enhanced ECL kit with Tanon5200 imaging system (Tanon, Shanghai, China).

\section{Plasmid transfection}

ERß plasmid was purchased from Sino Biological (Beijing, China) and extracted using an Endo-free Plasmid DNA Mini Kit I (OMEGA). Exponentially growing cells were seeded in 6-well plates overnight and transfected with ERß plasmids using Lipofectamine 2000 reagent.

\section{Live/Dead staining}

Cell viability was determined by the Live/Dead cytotoxicity tool kit for mammalian cells (Invitrogen $\circledast$ ). The green $(492 \mathrm{~nm})$ and red $(545 \mathrm{~nm})$ fluorescence were observed under a fluorescent microscope.

\section{MTT assay}

T47D and MDA-MB-231 cells $\left(1 \times 10^{4}\right.$ cell/well) were seeded into 96-well plates and cultured with indicated stimulations for indicated time. After treatment, cells were cultured with serum-free medium and $0.5 \mathrm{mg} / \mathrm{mL}$ MTT for additional $4 \mathrm{~h}$. After the removal of medium, $150 \mu \mathrm{L}$ DMSO was added to each well and the plates were shaken for $15 \mathrm{~min}$. The plates were then analyzed using a microplate reader (Bio-Rad, Hercules, CA, USA) using a wavelength of $490 \mathrm{~nm}$.

\section{Annexin V/PI staining}

Cells were plated into 6-well plates. After $24 \mathrm{~h}$ incubation, cells were treated as indicated for $48 \mathrm{~h}$. Then cells were harvested and suspended to stain with AnnexinV-FITC and PI. All stained cells were analyzed by FACS (ACEA NovoCyte, Agilent, USA). The obtained data were analyzed with NovoExpress software.

\section{Immunofluorescence}

Cells were stained with Mitotracker and then fixed with 4\% paraformaldehyde for $10 \mathrm{~min}$ and then blocked with $10 \%$ BSA for 30 min at room temperature. After this procedure, the cells were incubated with primary antibodies $(1: 200)$ at $37^{\circ} \mathrm{C}$ for $4 \mathrm{~h}$. Then, cells were incubated with an CoraLite488-conjugated anti-rabbit secondary antibody (1:50) at room temperature for $1 \mathrm{~h}$. The nucleus was stained with DAPI. Fluorescent signals were detected using an inverted fluorescence microscope (DM505, Nikon Co., Ltd., Otawara, Tochigi, Japan).

\section{Mitochondrial membrane potential $(\Delta \Psi \mathrm{m})$ assay}

Cells were plated into 6-well plates. After indicated treatment, the cells were harvested by trypsinization and stained with $100 \mathrm{nM}$ TMRE for $30 \mathrm{~min}$ at $37^{\circ} \mathrm{C}$ in the dark. $\Delta \Psi \mathrm{m}$ was detected by flow cytometry.

\section{Statistical analysis}


One-way analysis of variance (ANOVA) and further Dunnett's multiple comparison test were used and $P$ value $<0.05$ was considered statistically significant (Prism 6.0, GraphPad, La Jolla, CA, USA). Data are presented as mean \pm S.E.M.

\section{Results}

\section{TAD1822-7 induced ERß-mediated cell death in breast cancer cells}

Tumor suppressing effects of ERß has been found in breast cancer cells. To evaluate the potential regulation of ERß by TAD1822-7 in breast cancer cells, the protein levels of ERß were examined in TAD1822-7-treated T47D and MDA-MB-231 cells. As shown in Fig. 1b, TAD1822-7 increased ER $\beta$ expression in a concentration-dependent manner. To confirm the anti-tumor effects of ER $\beta, E R \beta$ overexpressing T47D and MDA-MB-231 cells were established (Fig. 1c). Live/dead cell staining was performed in breast cancer cells with transfected ER $\beta$ plasmids or treated ER $\beta$ specific agonist, diarylpropionitrile (DPN), as well as TAD1822-7. The data from MTT assay indicated that overexpression and activation of ER $\beta$ as well as TAD1822-7 induced cell death in T47D and MDA-MB-231 cells (Fig. 1d). Moreover, significant cell death indicated by the red fluorescence was induced when ER $\beta$ was overexpressed and activated, suggesting TAD1822-7 might inhibit breast cancer cell growth via the induction of ERß (Fig. 1e). Further analyses using Annexin V/PI staining were performed to confirm that TAD1822-7 induced ERß-mediated apoptosis in breast cancer cells (Fig. 1f).

\section{TAD1822-7 induced ERß-mediated mitochondrial dysfunction in breast cancer cells}

To further investigate the sub-cellular location of TAD1822-7-induced ER $\beta$, immunostaining of ER $\beta$ was performed. Similar to DPN-stimulated cells, TAD1822-7-increased ER $\beta$ was found to localize in cytoplasm and colocalized with a mitochondrial marker (Fig. 2a). Moreover, TAD1822-7-induced mitochondrial localization of ER $\beta$ led to a decrease of mitochondrial membrane potential assessed by TMRE staining, which was in line with the decreased mitochondrial membrane potential in ER $\beta$-transfected and DPNstimulated T47D and MDA-MB-231 cells (Fig. 2b).

\section{TAD1822-7 inhibited ERß-mediated PI3K-AKT pathways in breast cancer cells}

The expression of PI3K catalytic subunits, $\mathrm{p} 110 \mathrm{a}$ and $\mathrm{p} 110 \beta$, regulatory subunit $\mathrm{p} 85$, as well as AKT in both T47D and MDA-MB-231 cell lines were examined to further explore the regulatory mechanisms of TAD1822-7 in breast cancer cells. In accordance with ERß-transfected and DPN-stimulated cells (Fig. 3a and b), TAD1822-7 reduced the protein levels of p110a, p110ß, p-p85 and p-AKT in a concentrationdependent manner (Fig. 3c). These results indicated that TAD1822-7 inhibited ERß-mediated PI3K-AKT pathways in breast cancer cells. 


\section{TAD1822-7 inhibited autophagy in breast cancer cells}

As mitochondrial dysfunction is likely to result in the modulation of autophagy [13], we speculated that TAD1822-7 regulates autophagy in breast cancer cells. As shown in Fig. 4a, increased LC3-II protein levels suggested the accumulation of LC3-II and formation of autophagosomes. While, elevated levels of p62 indicated the inhibition of autophagy by TAD1822-7 in T47D and MDA-MB-231 cells. Similarly, ER $\beta$ transfection and DPN also inhibited autophagy in breast cancer cells (Fig. $4 \mathrm{~b}$ and c).

\section{Inhibition of autophagy contributed TAD1822-7-induced cell death in breast cancer cells}

Dual roles of autophagy are being increasingly recognized that autophagy either suppresses or supports tumor cell growth [14]. To further identify the role of TAD1822-7-induced autophagy in cell death, cell viability was determined in TAD1822-7 and in the presence of autophagy inhibitors, including vacuolar H+-ATPase inhibitor, bafilomycin (Baf), lysosomal inhibitor, chloroquine (CQ), and mitophagy inhibitor, mdivi-1 (Mdv). In both T47D and MDA-MB-231 cells, significant stronger inhibition of cell viability was observed in TAD1822-7 and Mdv combined treated cells in comparison with TAD1822-7 alone treated cells (Fig. 4d). We further assess cell apoptosis in T47D and MDA-MB-231 cells treated with the combination of TAD1822-7 and Mdv. Consistently, further elevated apoptotic cell numbers were found in TAD1822-7- and Mdv-treated cells (Fig. 4e). Taken together, TAD1822-7-inhibited autophagy contributed TAD1822-7-induced cell death in breast cancer cells.

\section{TAD1822-7 controlled HIF-1 $\beta$ pathways by ER $\beta$ induction in hypoxic breast cancer cells}

Consistent with the literature that ER $\beta$ suppresses HIF-1 activation via the downregulation of HIF-1 $\beta$ [11], the evaluation of HIF-1 $\alpha$ and HIF-1 $\beta$ protein levels revealed that ER $\beta$ transfection and ER $\beta$ agonist treatment reduced the protein levels of HIF-1 $\beta$ but not HIF-1a (Fig. 5a and b). TAD1822-7 treatment remained consistent downregulation of HIF-1 $\beta$ in company with the upregulation of ER $\beta$ expression (Fig. $5 c)$.

\section{TAD1822-7 inhibited hypoxia-induced autophagy and PI3K- AKT pathways by ER $\beta$ induction in breast cancer cells}

The levels of autophagy related proteins were evaluated in hypoxic T47D and MDA-MB-231 cells under the treatment of TAD1822-7 and ER $\beta$ transfection. As shown in Fig. 6a, both treatments resulted in an inhibition of hypoxia-induced autophagy indicated by the enhancement of LC3-II levels and p62. Furthermore, as hypoxia regulates cellular functions through PI3K-AKT signaling, the regulation of $\mathrm{p} 110 \mathrm{a}$, p110 $\beta$, p-p85 and p-AKT by TAD1822-7 and ER $\beta$ transfection in hypoxic cells was determined and the data indicated that TAD1822-7 and ER $\beta$ transfection inhibited hypoxia-induced PI3K-AKT pathway proteins (Fig. 6b). These data suggested that TAD1822-7 inhibited hypoxia-induced autophagy and PI3KAKT pathways by ER $\beta$ induction in breast cancer cells. 


\section{Discussion}

ER $\beta$ has been recognized to play an important role in prevention of breast cancer development and metastasis. In this study, we found that TAD1822-7 could hinder breast cancer cell growth owing to upregulation of ERß levels and inhibition of PI3K/AKT pathways. Further mechanistic studies revealed that TAD1822-7 initiated mitochondrial dysfunction and autophagy but blocked the late-stage autolysosome formation, thereby resulted in cell death. In addition, TAD1822-7-induced cell death was further enhanced by mitophagy inhibitor confirmed TAD1822-7-regulated autophagy sensitized breast cancer cells to TAD1822-7. Moreover, TAD1822-7 inhibited HIF-1 $\beta$ expression through the upregulation of ER $\beta$ in hypoxic breast cancer cell models, and the underlying mechanism was further demonstrated to be $\mathrm{PI} 3 \mathrm{~K} / \mathrm{AKT}$ pathway mediated actions.

The expression level of ER $\beta$ decreases from the highest values in normal tissue to almost absent in advanced tumors during the development of breast cancer. To date, the prevalent treatment strategies of hormone-sensitive tumors ( 75\% of breast cancer) are based on the use of ERa-targeting drugs. Whereas, lacking of therapeutic targets, triple-negative breast cancer, accounting for $\sim 15 \%$ of all breast cancer, is known to be more aggressive with worse prognosis compared to ERa-positive breast cancer [15]. Recently, great efforts have been focused on the identification of new ER $\beta$ agonists and some natural molecules have showed selectivity for ER $\beta$ and promising effects on proliferation, inhibition and invasiveness suppression against breast cancer [16-18]. In this work, we found that TAD1822-7 inhibits the cell growth in both T47D (ERa+/ER + ) and MDA-MB-231 (ERa-/ER $\beta+)$ cells via the upregulation of $E R \beta$. ER $\beta$ induces apoptosis via anti-apoptotic proteins inhibitors of apoptosis proteins, apoptotic proteins in BCL-2 family and caspases [19, 20]. Moreover, ER $\beta$-modulated autophagy has also been noticed, including the increase of LC3-II indicating the initiation of autophagy and formation of autophagosomes. However, the regulation of p62 is much less documented. Our results demonstrated that ER $\beta$ increased the inversion of LC3-I to LC3-II and the expression of p62, suggesting TAD1822-7 triggers autophagy and blocks the late-stage autolysosome formation via the upregulation of ER $\beta$, which increases cellular stress and eventually leads to cell death. In consistency with the literature [6], our findings also demonstrate that ER $\beta$ affects PI3K/AKT pathway to regulate autophagy.

Rapid growth of tumor cells generates a hypoxia local environment which influences a set of cellular functions, such as angiogenesis, erythropoiesis, energy metabolism, metastasis and autophagy [21]. HIF1 complexes are responsible for the regulation of these cellular functions via the control of HIF-1 target genes, including vascular endothelial growth factor (VEGF), erythropoietin and chemokine receptor CXCR4 [22]. Our finding confirmed the study showing that TAD1822-7-induced ERß inhibits HIF-1mediated functions through the downregulation of HIF-1 $\beta$. These results may further reveal the mechanism of our previous finding, TAD1822-7 inhibits the invasion of breast cancer via CXCR4 inhibition [9], is that TAD1822-7 inhibits HIF-1 $\beta$ so as to downregulate HIF-1 target gene CXCR4. Probably, for the same reason, TAD1822-7 inhibits VEGF and therefore angiogenesis in tumor cells. 
Our study reported new findings that TAD1822-7 upregulates ER $\beta$ leading to breast cancer cell death. Mechanistically, we demonstrated that the inhibitory effects of TAD1822-7-upregulated ER $\beta$ on the cell proliferation and apoptosis of breast cancer cells were mediated by PI3K/AKT signaling pathways which induce mitochondrial dysfunction and autophagy. Moreover, TAD1822-7 modulates HIF functions and autophagy via the inhibition of HIF-1 $\beta$ in the context of hypoxia-induced autophagy. These findings provide new insight into the mechanism underlying the inhibitory effects of TAD1822-7 in breast cancer cells.

\section{Declarations}

\section{Acknowledgement}

This study was supported by the National Natural Science Foundation of China (Grant no. 81773772 and no. 81903643) and the Fundamental Research Funds for the Central Universities.

\section{Author contributions}

QS performed the experiments and drafted the paper. QW and KC performed the experiments. JW and AS collected and analyzed the data. QS and YZ designed the study and acquired the funding.

\section{Data availability}

The analyzed data are available from the corresponding author on reasonable request Declarations

\section{Conflict of interests}

The authors declare that they have no known competing financial interests or personal relationships that could have appeared to influence the work reported in this paper.

\section{Consent to participate}

All authors have seen the manuscript and approved to submit the manuscript.

\section{Consent for publication}

All authors consent to the publication of the manuscript.

\section{Ethical approval}


Present study was conducted after the prior approval by the biomedical ethics committee of Xi'an Jiaotong University Health Science Center and conform to ethical principles.

\section{References}

1. Sung H, Ferlay J, Siegel RL, Laversanne M, Soerjomataram I, Jemal A et al (2021) Global cancer statistics 2020: GLOBOCAN estimates of incidence and mortality worldwide for 36 cancers in 185 countries. CA Cancer J Clin 71:209-249

2. Clarke R, Tyson JJ, Dixon JM (2015) Endocrine resistance in breast cancer-An overview and update. Mol Cell Endocrinol 418:220-234

3. Mal R, Magner A, David J, Datta J, Vallabhaneni M, Kassem M et al (2020) Estrogen receptor beta (ERB): a ligand activated tumor suppressor. Front Oncol 10:587386

4. Zhou Y, Liu X (2020) The role of estrogen receptor beta in breast cancer. Biomark Res 8:39

5. Galluzzi L, Pietrocola F, Bravo-San Pedro JM, Amaravadi RK, Baehrecke EH, Cecconi F et al (2015) Autophagy in malignant transformation and cancer progression. EMBO J 34:856-880

6. Yang ZM, Yang MF, Yu W, Tao HM (2019) Molecular mechanisms of estrogen receptor $\beta$-induced apoptosis and autophagy in tumors: implication for treating osteosarcoma. J Int Med Res 47:46444655

7. Song P, Li Y, Dong Y, Liang Y, Qu H, Qi D et al (2019) Estrogen receptor $\beta$ inhibits breast cancer cells migration and invasion through CLDN6-mediated autophagy. J Exp Clin Cancer Res 38:354

8. Moscat J, Karin M, Diaz-Meco MT (2016) p62 in Cancer: Signaling Adaptor Beyond Autophagy. Cell 167:606-609

9. Vaupel P, Höckel M, Mayer A (2007) Detection and characterization of tumor hypoxia using p02 histography. Antioxid Redox Signal 9:1221-1235

10. McKeown SR (2014) Defining normoxia, physoxia and hypoxia in tumours-implications for treatment response. Br J Radiol 87:20130676

11. Lim W, Park Y, Cho J, Park C, Park J, Park Y-K et al (2011) Estrogen receptor beta inhibits transcriptional activity of hypoxia inducible factor- 1 through the downregulation of arylhydrocarbon receptor nuclear translocator. Breast Cancer Res 13:32

12. Zhan Y, Zhang H, Li J, Zhang Y, Zhang J, He L (2015) A novel biphenyl urea derivate inhibits the invasion of breast cancer through the modulation of CXCR4. J Cell Mol Med 19:1614-1623

13. Wang R, Wang G (2019) Autophagy in Mitochondrial Quality Control. Adv Exp Med Biol 1206:421434

14. Levy JMM, Towers CG, Thorburn A (2017) Targeting autophagy in cancer. Nat Rev Cancer 17:528542

15. Sellitto A, D'Agostino Y, Alexandrova E, Lamberti J, Pecoraro G, Memoli D et al (2020) Insights into the role of estrogen receptor $\beta$ in triple-negative breast cancer. Cancers (Basel) 12:1477 
16. Mersereau JE, Levy N, Staub RE, Baggett S, Zogovic T, Chow S et al (2008) Liquiritigenin is a plantderived highly selective estrogen receptor beta agonist. Mol Cell Endocrinol 283:49-57

17. Middleton E Jr, Kandaswami C, Theoharides TC (2000) The effects of plant flavonoids on mammalian cells: implications for inflammation, heart disease, and cancer. Pharmacol Rev 52:673751

18. Setchell KD, Clerici C, Lephart ED, Cole SJ, Heenan C, Castellani D et al (2005) S-equol, a potent ligand for estrogen receptor beta, is the exclusive enantiomeric form of the soy isoflavone metabolite produced by human intestinal bacterial flora. Am J Clin Nutr 81:1072-1079

19. Tao X, Xu L, Yin L, Han X, Qi Y, Xu Y et al (2017) Dioscin induces prostate cancer cell apoptosis through activation of estrogen receptor- $\beta$. Cell Death Dis 8:e2989

20. Paruthiyil S, Cvoro A, Zhao X, Wu Z, Sui Y, Staub RE et al (2009) Drug and cell type-specific regulation of genes with different classes of estrogen receptor beta-selective agonists. PLoS One 4:e6271

21. Choudhry H, Harris AL (2018) Advances in Hypoxia-Inducible Factor Biology. Cell Metab 27:281-298

22. Xiang L, Semenza GL (2019) Chapter Five - Hypoxia-inducible factors promote breast cancer stem cell specification and maintenance in response to hypoxia or cytotoxic chemotherapy. In: Civin $\mathrm{Cl}$, Kingsbury TJ, Kim M, Fisher PB (eds) Advances in Cancer Research, 141. Academic Press, pp 175212

\section{Figures}



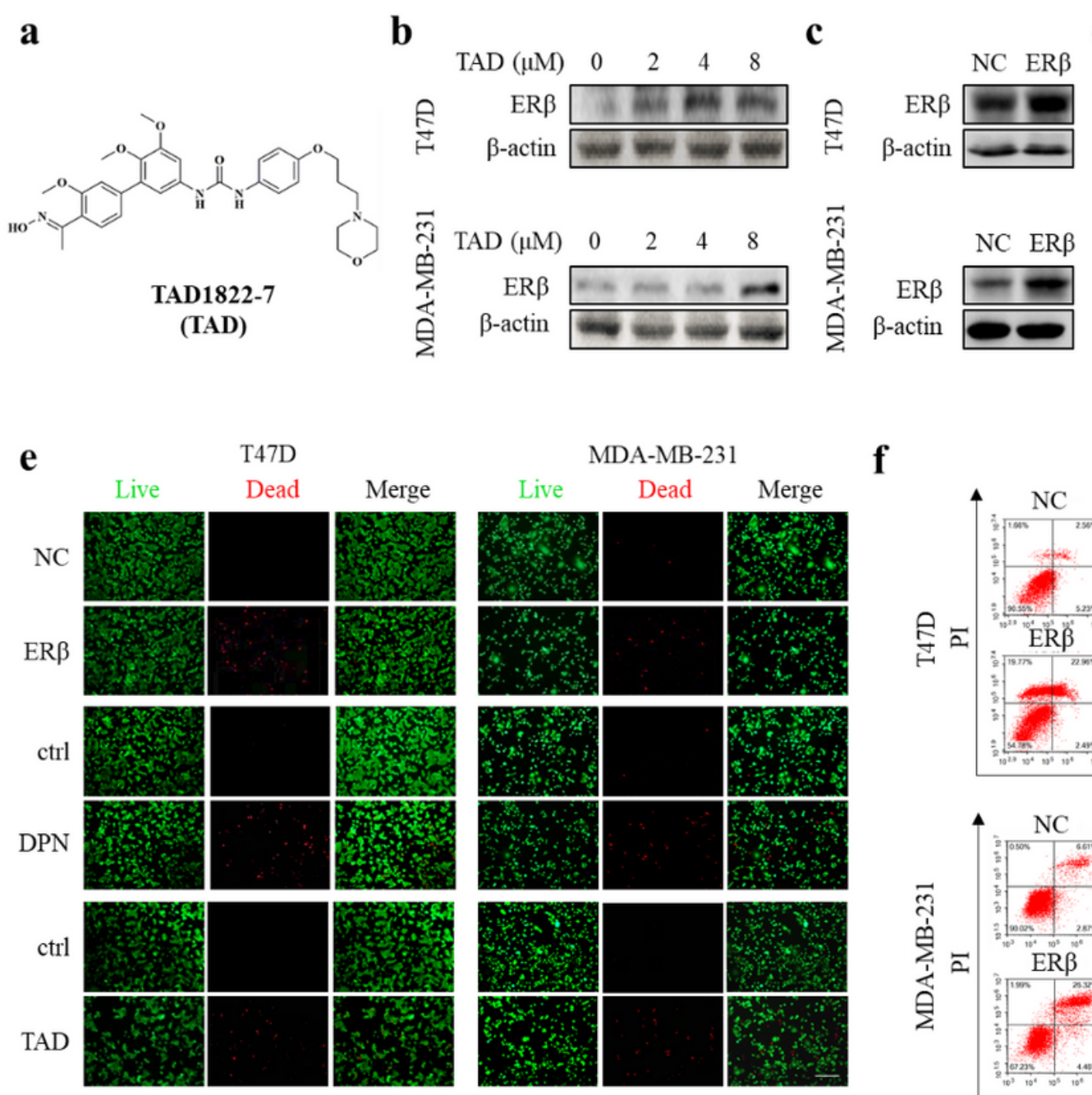

f
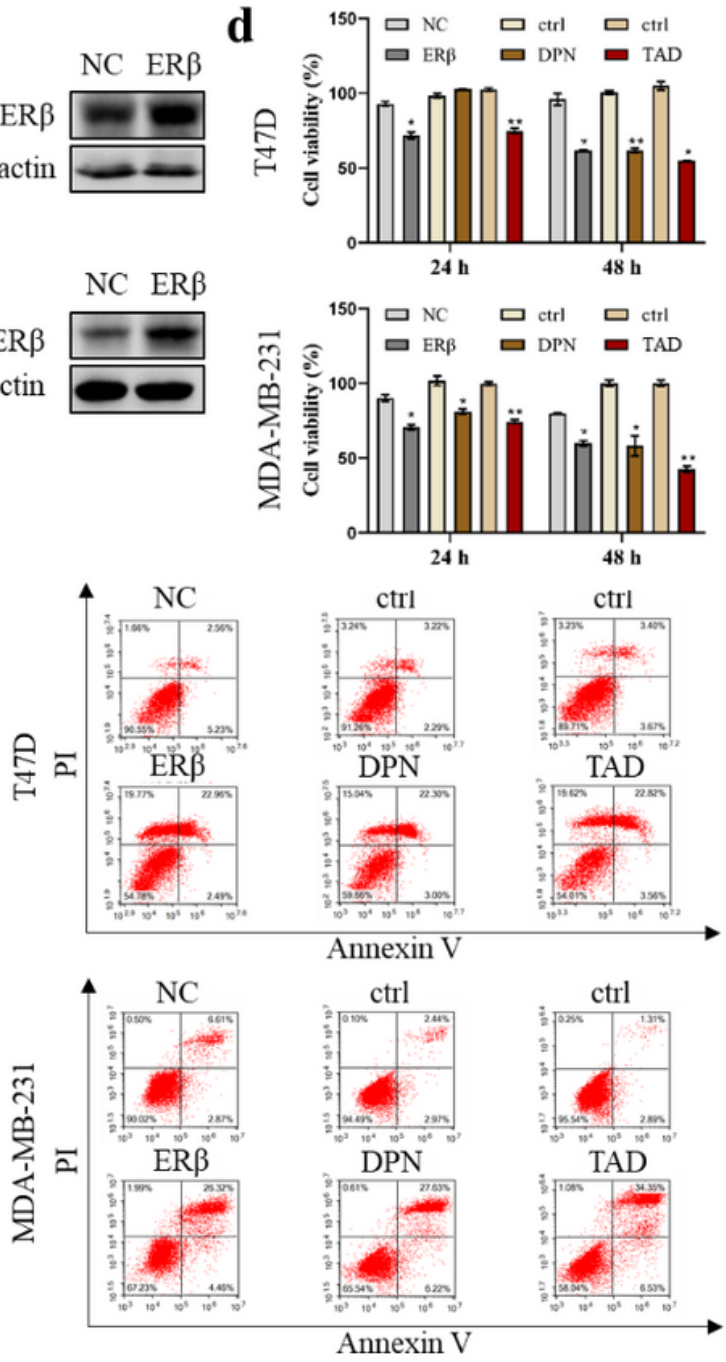

\section{Figure 1}

TAD1822-7 (TAD) induced ERß-mediated cell death in breast cancer cells. a Chemical structure of TAD1822-7. $b$ T47D and MDA-MB-231 cells were treated with different concentrations of TAD1822-7 for 24h. ER $\beta$ protein levels were examined by western blotting. c T47D and MDA-MB-231 cells were transfected with NC (negative control) or ER $\beta$ plasmids. After $24 \mathrm{~h}, \mathrm{ER} \beta$ protein levels were determined by western blotting. $\beta$-actin served as controls. $d$ T47D and MDA-MB-231 cells were transfected with ER $\beta$ plasmids or treated with $100 \mathrm{nM}$ DPN or TAD for $48 \mathrm{~h}$. Live and dead cells were stained with $1 \mu \mathrm{M}$ calcein-AM and $1 \mathrm{mg} / \mathrm{mL}-1$, respectively. The results shown were representative of 3 independent experiments. e T47D and MDA-MB-231 cells were transfected with ERß plasmids or treated with DPN or TAD for 24 and $48 \mathrm{~h}$, and the cell viability was examined by MTT assay $(n=3) .{ }^{\star} p<0.05,{ }^{\star \star} p<0.01$, ${ }^{\star \star \star} p$ $<0.001$ one-way ANOVA followed by Dunnett's posttest in comparison with untreated control. $f$ Cell apoptosis was measured by Annexin V-FITC/PI staining. The percentage of apoptotic cells is indicated. The results shown were representative of 3 independent experiments. 
a

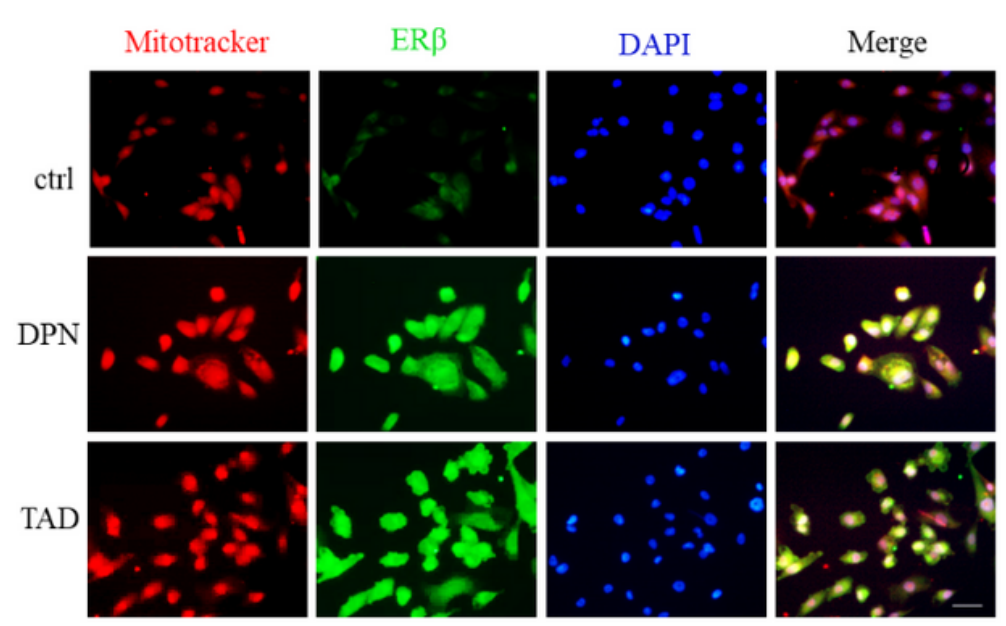

b
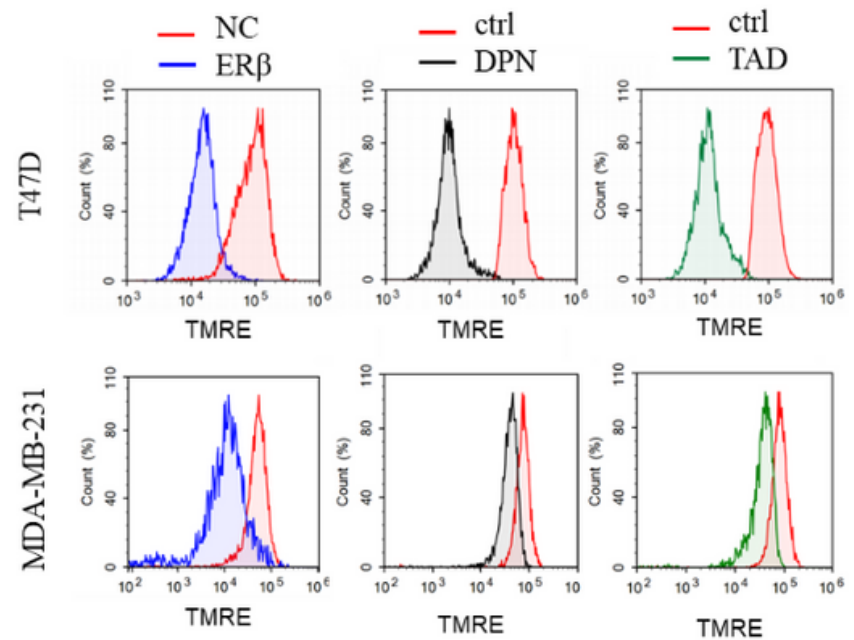

\section{Figure 2}

TAD1822-7 induced ERß-mediated mitochondrial dysfunction in breast cancer cells. a MDA-MB-231 cells were treated with DPN or TAD for $24 \mathrm{~h}$. Mitotracker (red), ERß (green), DAPI (blue) staining and 3-channel merged images indicated the colocalization of mitochondria and ER $\beta$. Scale bars, $50 \mu \mathrm{m}$. b T47D and MDA-MB-231 cells were transfected with ER $\beta$ plasmids or treated with DPN or TAD for $48 \mathrm{~h}$. Mitochondrial membrane potential was measured by TMRE staining. The results shown were representative of 3 independent experiments. 
$\mathbf{a}$

\begin{tabular}{|c|c|c|c|c|c|c|c|c|c|c|c|}
\hline & $\mathrm{NC} \quad \mathrm{ER} \beta$ & & & $\mathrm{NC} \quad \mathrm{ER} \beta$ & b & DPN & - & + & & DPN & - \\
\hline $\mathrm{p} 110 \alpha$ & 18 & & $\mathrm{p} 110 \alpha$ & & & $\mathrm{p} 110 \alpha$ & $\infty$ & 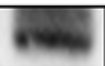 & & $\mathrm{p} 110 \alpha$ & $\omega$ \\
\hline $\mathrm{p} 110 \beta$ & 9: & $\bar{m}$ & $\mathrm{p} 110 \beta$ & 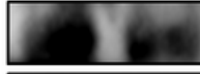 & & $\mathrm{p} 110 \beta$ & -7 & 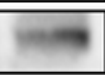 & $\bar{m}$ & $\mathrm{p} 110 \beta$ & \\
\hline p-p85 & 60 & $\ddot{\theta}$ & p-p85 & is & 2 & p-p85 & $\infty$ & 6 & $\ddot{\theta}$ & p-p85 & \\
\hline p-AKT & $5=$ & $\sum_{4}^{i}$ & $\mathrm{p}-\mathrm{AKT}$ & as & $\stackrel{+}{H}$ & $\mathrm{p}-\mathrm{AKT}$ & $\bar{z}$ & & $\stackrel{3}{4}$ & $\mathrm{p}-\mathrm{AKT}$ & 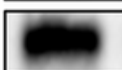 \\
\hline AKT & 20 & 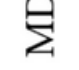 & $\mathrm{AKT}$ & & & AKT & & & $\sum$ & AKT & \\
\hline$\beta$-actin & -- & & $\beta$-actin & & & $\beta$-actin & $=$ & $\omega$ & & $\beta$-actin & $\bar{E}$ \\
\hline
\end{tabular}

C
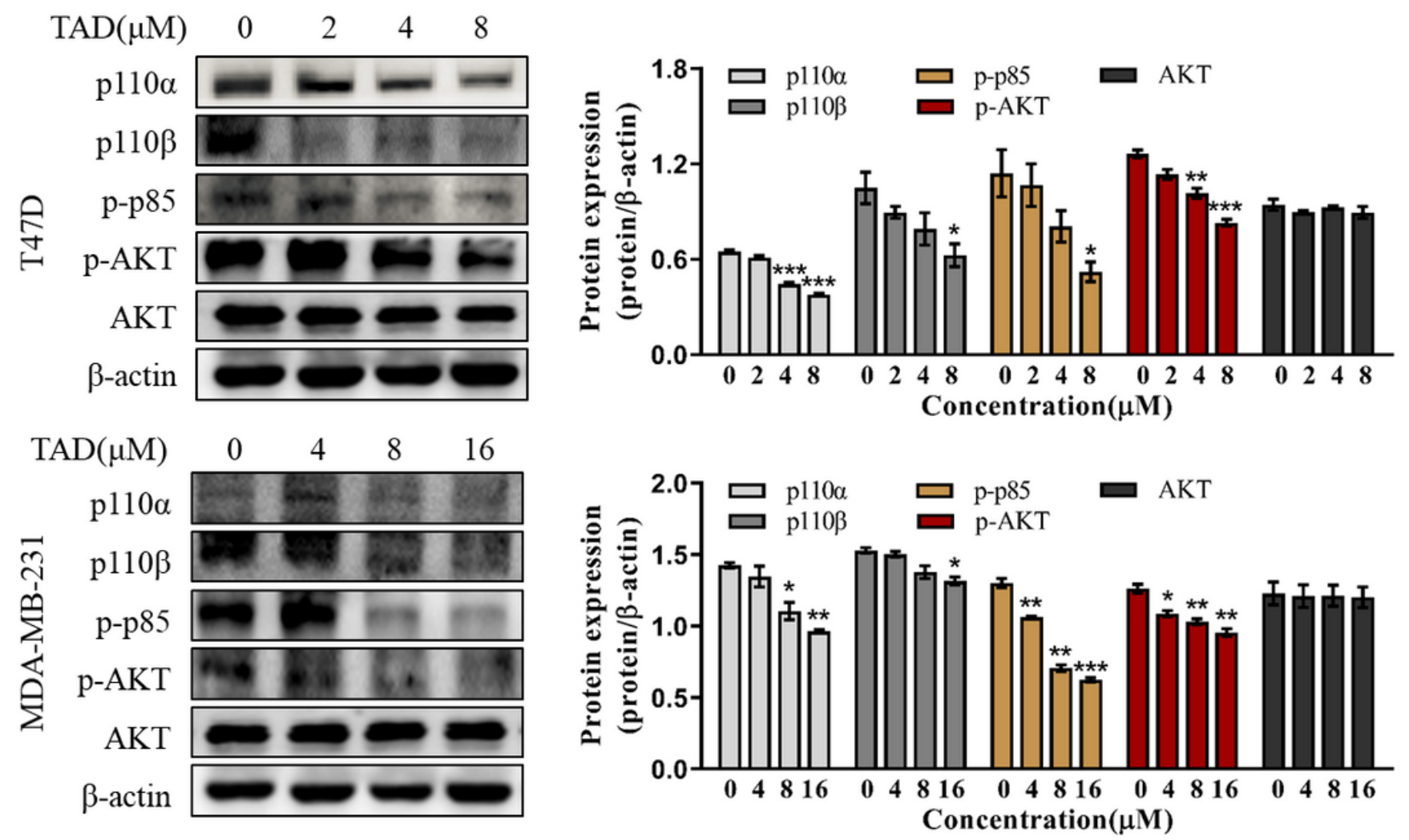

Figure 3

TAD inhibited ERß-mediated PI3K-AKT pathways in breast cancer cells. a T47D and MDA-MB-231 cells were transfected with ER $\beta$ plasmids for $24 \mathrm{~h}$. b T47D and MDA-MB-231 cells were treated with DPN for 24 h. C. T47D and MDA-MB-231 cells were treated with TAD for 24 h. p110a, p110ß, p-p85, p-AKT and AKT protein levels were assessed by western blotting. $\beta$-actin served as controls. The data shown were representative of 3 independent experiments. Quantification plots are shown on the right. ${ }^{\star} p<0.05,{ }^{*} \mathrm{p}$ $<0.01,{ }^{\star \star \star} \mathrm{p}<0.001$ one-way ANOVA followed by Dunnett's posttest in comparison with control. 

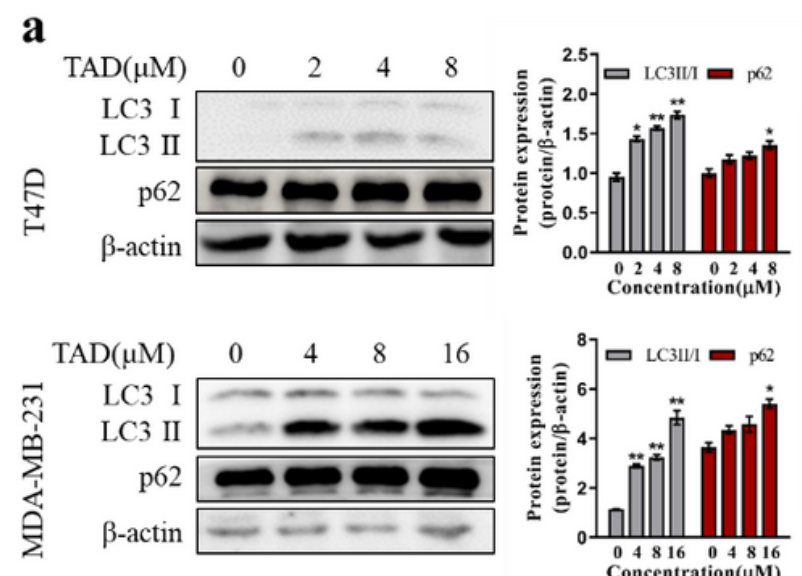

b

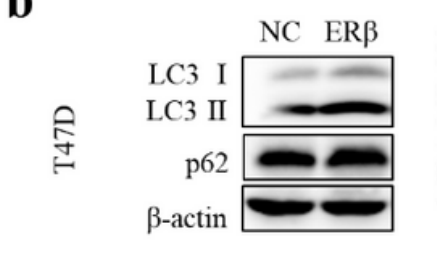

c
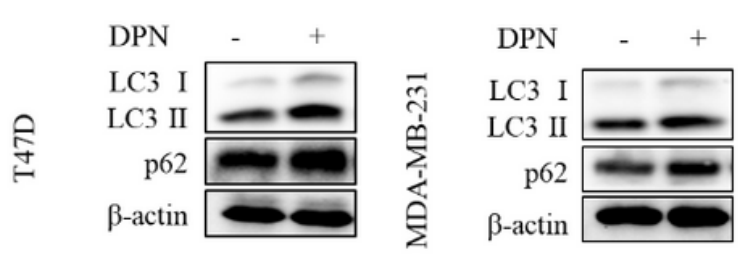

d
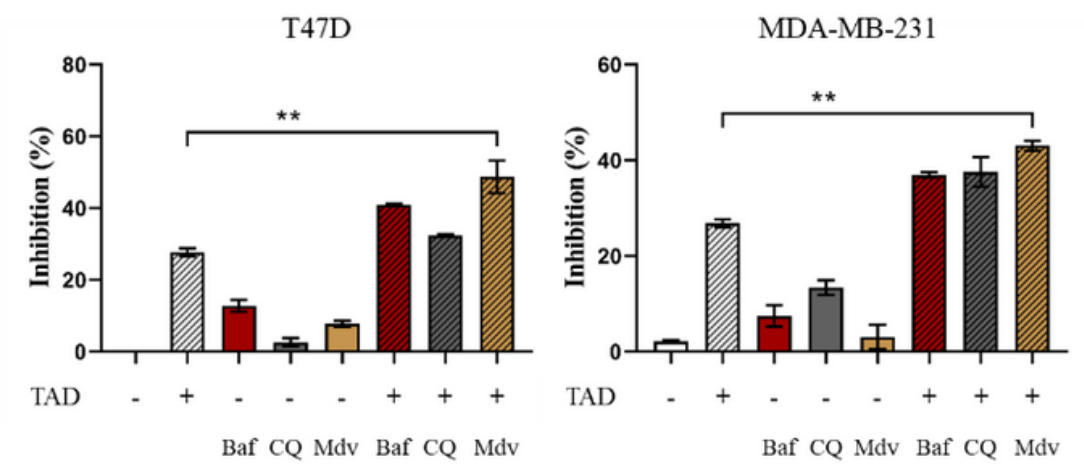

e

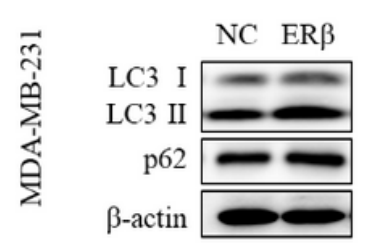

T47D

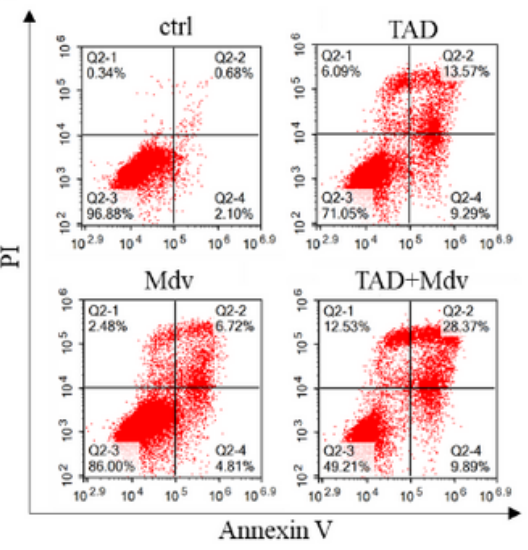

MDA-MB-231

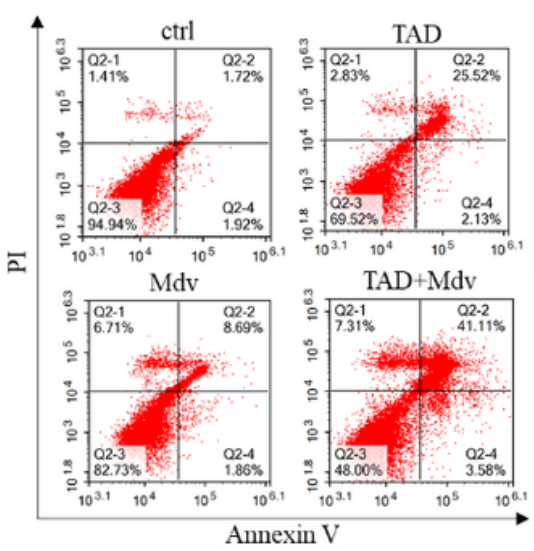

\section{Figure 4}

TAD inhibited autophagy in breast cancer cells contributing TAD-induced apoptosis in breast cancer cells.. a T47D and MDA-MB-231 cells were treated with different concentrations of TAD for $24 \mathrm{~h}$. B. T47D and MDA-MB-231 cells were transfected with ER 3 plasmids for $24 \mathrm{~h}$. c T47D and MDA-MB-231 cells were treated with DPN for $24 \mathrm{~h}$. LC3 and p62 protein levels were assessed by western blotting. $\beta$-actin served as controls. The data shown were representative of 3 independent experiments. Quantification plots are shown on the right. ${ }^{*} p<0.05, * * p<0.01$ one-way ANOVA followed by Dunnett's posttest in comparison with control.d T47D and MDA-MB-231 cells were treated with TAD1822-7 in the presence of $20 \mathrm{nM}$ Baf, $20 \mu \mathrm{M}$ CQ or $10 \mu \mathrm{M}$ Mdv for $48 \mathrm{~h}$. Cell cytotoxicity was analyzed by MTT. e T47D and MDA-MB-231 cells were treated with TAD in the presence of $10 \mu \mathrm{M} \mathrm{Mdv}$ for $48 \mathrm{~h}$. Cell apoptosis was measured by Annexin VFITC/PI staining. The data shown were representative of 3 independent experiments. 
a

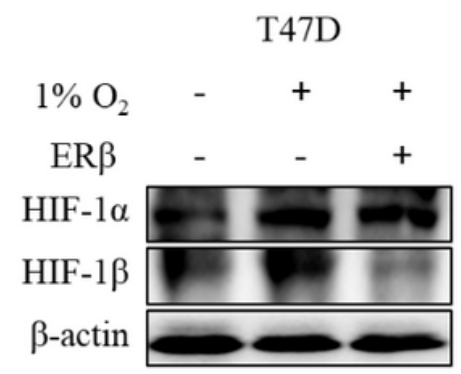

b

c

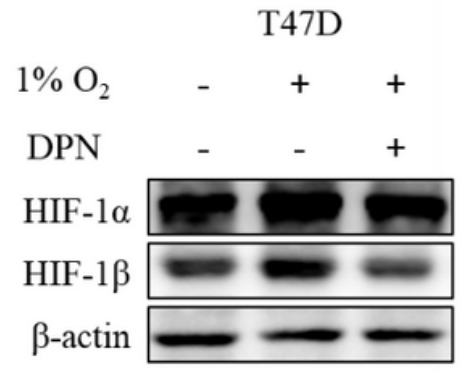

T47D

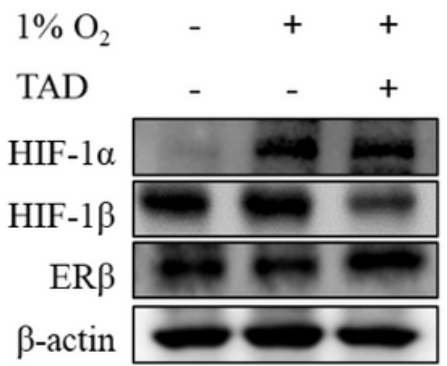

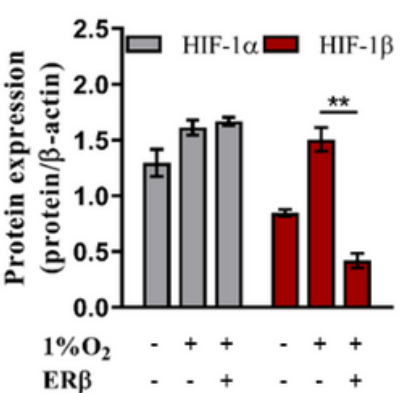
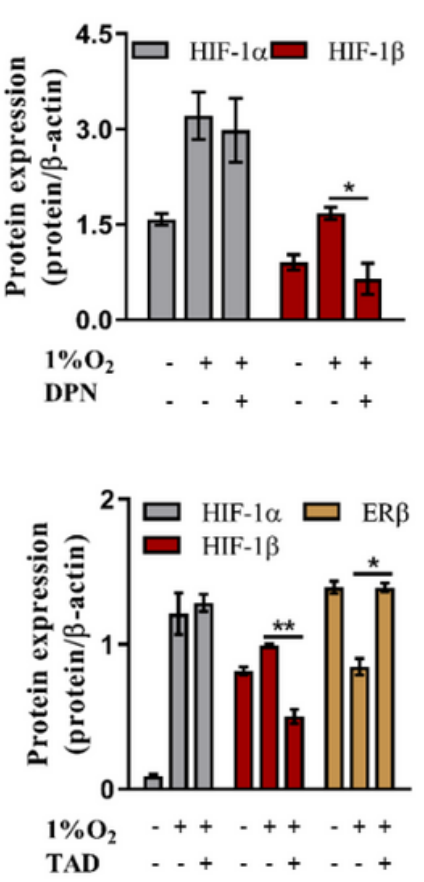
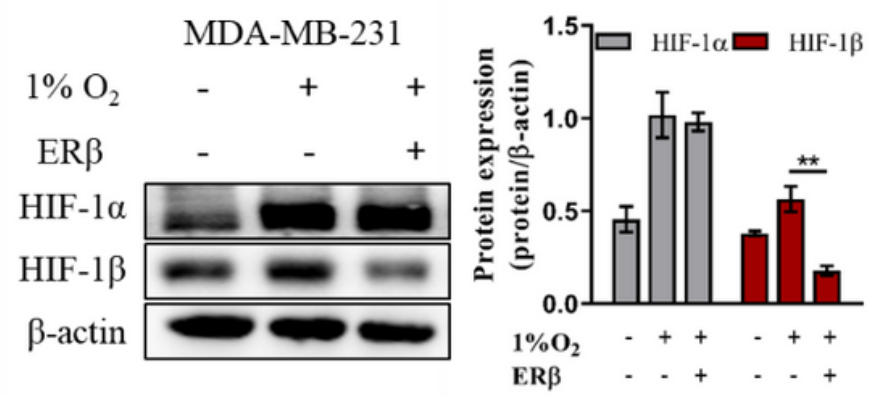

MDA-MB-231

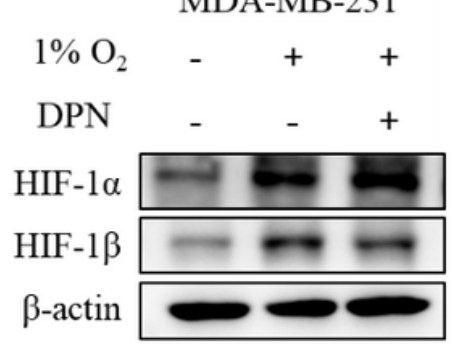

MDA-MB-231
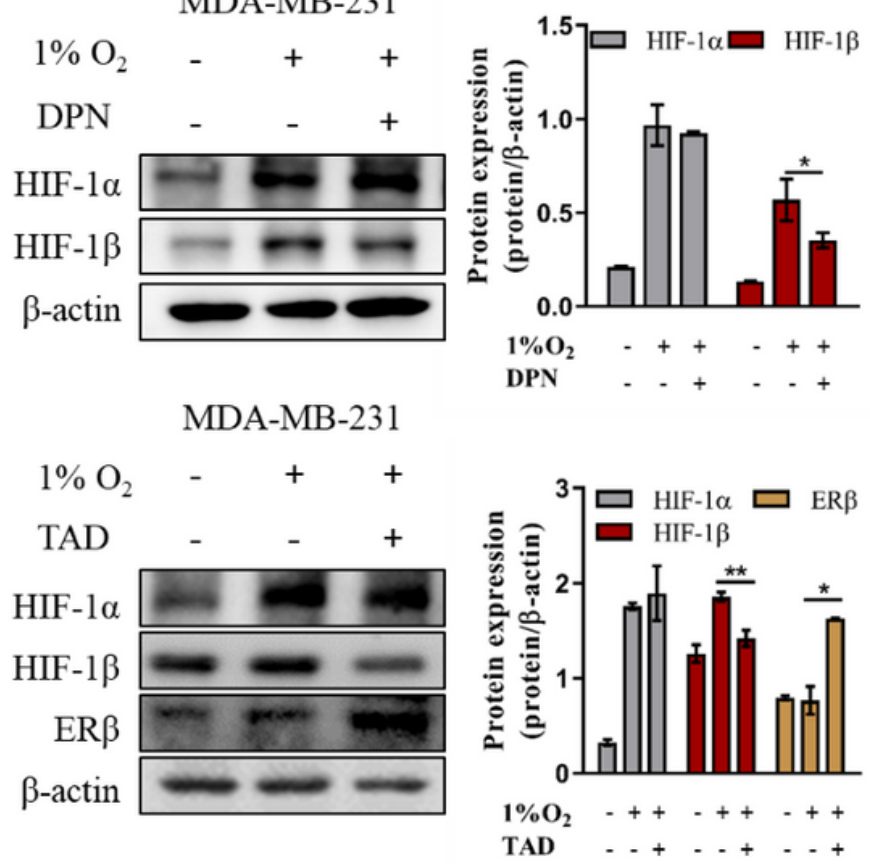

\section{Figure 5}

TAD1822-7 controlled HIF-1 $\beta$ pathways by ER $\beta$ induction in hypoxic breast cancer cells. a T47D and MDA-MB-231 cells were transfected with ER $\beta$ plasmids and incubated in $1 \% 02$ for $24 \mathrm{~h}$. b T47D and MDA-MB-231 cells were treated with DPN for 24 h. c T47D and MDA-MB-231 cells were treated with TAD for $24 \mathrm{~h}$. HIF-1a and HIF-1 $\beta$ protein levels were determined by western blotting. Representative result of 3 independent experiments. $\beta$-actin served as controls. Quantification plots are shown on the right. * $p<$ $0.05,{ }^{*} \mathrm{p}<0.01$ one-way ANOVA followed by Dunnett's posttest in comparison as indicated. 

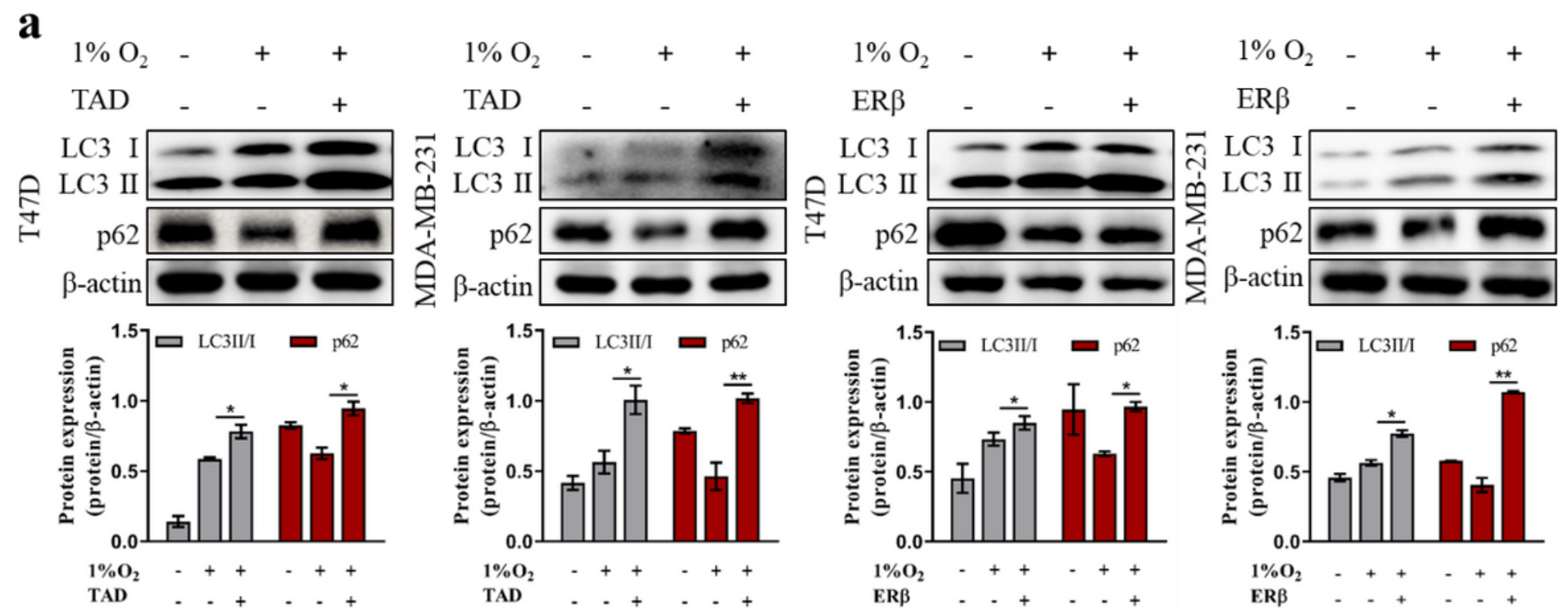

b $\underset{\mathrm{TAD}}{1 \% \mathrm{O}_{2}}-\quad+\quad+\quad+$
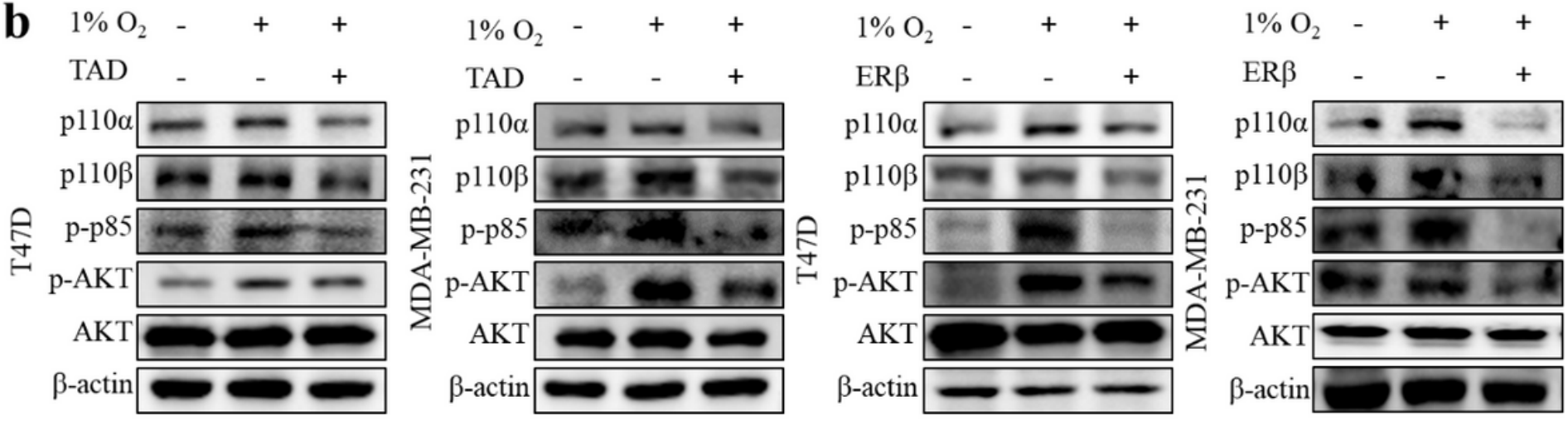

Figure 6

TAD1822-7 inhibited hypoxia-induced autophagy and PI3K-AKT pathways by ER $\beta$ induction in breast cancer cells. a T47D and MDA-MB-231 cells were treated with TAD or transfected with ER $\beta$ plasmids and incubated in $1 \% 02$ for $24 \mathrm{~h}$. LC3 and p62 protein levels were determined by western blotting.

Quantification plots are shown below. ${ }^{*} p<0.05,{ }^{*} \mathrm{p}<0.01$ one-way ANOVA followed by Dunnett's posttest in comparison as indicated. b T47D and MDA-MB-231 cells were treated with TAD or transfected with ER $\beta$ plasmids and incubated in 1\% 02 for $24 \mathrm{~h}$. p110a, p110ß, p-p85, p-AKT and AKT protein levels were assessed by western blotting. Representative result of 3 independent experiments. $\beta$-actin served as controls. 